\title{
Electric field criteria for charge packet formation and movement in XLPE
}

\author{
A. See, L.A. Dissado, J.C. Fothergill \\ Department of Engineering, University of Leicester, UK
}

\begin{abstract}
The formation of space charge packets in XLPE (Cross-linked polyethylene) tapes from unaged cable insulation has been studied utilising the pulsed electro-acoustic (PEA) technique. The $150 \mu \mathrm{m}$ thick sheets were studied under constant applied dc field of $120 \mathrm{kV} / \mathrm{mm}$ at a temperature of $20{ }^{\circ} \mathrm{C}$ for a period of 48 hours. After an inception period of about 3.5 hours, during which heterocharge accumulates at the anode and increases the local field there, a sequence of positive charge packets were observed to transit the sample starting from near the anode. This is shown as a moving image at the following web site: <include web site address here >. Calculation of the internal field showed that the packets required a field of $\geq$ $140 \mathrm{kV} / \mathrm{mm}$ for their initiation. Reduction of the applied field step-wise from $120 \mathrm{kV} / \mathrm{mm}$ to $80 \mathrm{kV} / \mathrm{mm}$ indicated that the charge packet would keep moving as long as the local field at its front exceeded $100 \mathrm{kV} / \mathrm{mm}$, but with a reducing magnitude. A return to an applied field of $120 \mathrm{kV} / \mathrm{mm}$ confirmed that the local field required to initiate a new packet was in excess of $135 \mathrm{kV} / \mathrm{mm}$. The results are discussed in terms of current theories of charge packet formation. The first packet appears to be a moving front of field ionisation. The generation of subsequent packets is governed by the field at the anode and the balance of charge
\end{abstract}


injection and extraction process, which occur there. The nature of the negative charges produced at the ionisation front is not clear, but they are unlikely to be electrons.

\section{INTRODUCTION}

The advent of experimental techniques capable of directly measuring the density of space charge in insulators under voltage in a non-destructive manner [1-4] has revealed the existence of charge packet formation at high DC fields. In these circumstances space charge is observed to cross the insulation in the form of a packet rather than through the steady advance of a charge front. Such packets have been observed both in cable insulation $[5,6]$, and in thin films (see for example [7,8,9]), and are now a widely accepted phenomenon in polymers. Since they occur at high fields before an electric failure occurs they are of interest as a possible pre-breakdown phenomenon. Although no direct correlation has yet been made with time-to-breakdown, the packet phenomenon leads to oscillating currents and nonstationary behaviour under DC conditions and might therefore lead to the transfer of energy to the polymer which may eventually result in breakdown. They will certainly lead to highfield current noise that may be an indicator of the imminence of breakdown. For this reason there is an interest in understanding the phenomena. Currently there are three models that are capable of giving charge packet formation. In one case [6] the packet is formed by injected charges and moves across the sample as a packet of excess charge carriers. Usually these

packets are small in magnitude $\left(1-10 \mathrm{Cm}^{-3}\right)$ and spread out as the packet moves so that the packet loses its identity as it crosses the sample. This type of packet can only be re-created a few times. A different model for packet generation proposes field-induced dissociation as a source of carriers [5]. The packet is still, however, a region of slow moving charge carriers, and will also spread out during its passage. In an alternative model [8], field-assisted generation of carriers produces a depletion front in the form of a solitary wave. The packet does not spread out and can be recreated indefinitely as each packet approaches the counterelectrode. The charge density in these packets is much higher $\left(100 \mathrm{Cm}^{-3}\right)$. Evidence exists for the formation of each type of packet, however, the details of the packet formation is still unclear. Hozumi et al [5] has shown that heat treatment of XLPE samples containing 
acetophenone and anti-oxidant play a role in packet formation, but what form this takes has not been determined. In the experiments reported here we explore the electrical conditions required for the initiation of very slow moving charge packets in XLPE. We show that they can only be formed at fields above a 'critical' value, which can take a long time to develop. Once initiated long sequences of packet formation are possible. As it moves through the sample, each packet in the sequence maintains a field at its front that is sufficient to maintain movement. Reduction of the applied field from $120 \mathrm{kV} / \mathrm{mm}$ to $90 \mathrm{kV} / \mathrm{mm}$ allowed the field necessary to maintain packet movement to be determined. Even though the field at the packet front was less than that achieved at the higher applied fields the packet continued moving at the same speed but with reduced amplitude. A return to $120 \mathrm{kV} / \mathrm{mm}$ verified the existence of a critical onset field. These results are discussed in terms of the theoretical models.

\section{EXPERIMENTAL INVESTIGATIONS}

\subsection{Sample preparation}

The measurements were performed on tapes cut from unaged cross-linked polyethylene (XLPE) cables produced specifically for the project [10], by turning them on a lathe equipped with a specially designed cutting tool. The tapes had a width of $80 \mathrm{~mm}$ and mean thickness $150 \mu \mathrm{m}$. Before testing, specimens were cut from tapes from insulation located $3 \pm 1 \mathrm{~mm}$ from the inner screen. Each side of the specimen had a different roughness. Measurements using an atomic force microscope [10] showed that the roughness on the shiny (outer) face was typically $150 \mathrm{~nm}$, whilst that on the other face was $350 \mathrm{~nm}$. Specimens were pretreated in an oven for $48 \pm 1$ hours at $50 \pm 2{ }^{\circ} \mathrm{C}$, atmospheric condition in order to expel most of the cross-linking by-products. Measurements by FTIR and HPLC revealed that they were below the detection limit by these techniques after this treatment [10], although photoluminescence showed strong evidence for the persistence of spectral features associated with these byproducts. Further out gassing did not induce a marked change in the photoluminescence spectrum indicating that these luminescent centres are probably chemically linked to the chain. 
Space charge observations were made by the pulsed electro-acoustic technique (PEA) at various constant dc-voltage levels systematically varied corresponding to applied fields between $80 \mathrm{kV} / \mathrm{mm}$ and $120 \mathrm{kV} / \mathrm{mm}$. The samples were not coated with electrodes but were clamped between two electrodes. The cathode was a solid aluminium electrode, which was ground to an optically flat finish. This was in contact with the rougher face of the specimen. The anode was constructed from $0.75 \pm 0.03 \mathrm{~mm}$ thick piece of semicon from a commercial XLPE cable that was coated with a $1 \pm 0.2 \mu \mathrm{m}$ thick layer of $99.9 \%$ pure aluminium. The anode was in contact with the smooth face of the specimen. A thin $(\sim 0.2 \mu \mathrm{m})$ film of silicon oil was used in all experiments on both the top and bottom electrodes to aid acoustic transmission. All measurements were made in air at atmospheric pressure.

\subsection{Pulsed Electro-acoustic apparatus}

The principle of space charge measurement using the PEA technique is well known and reported elsewhere $[11,12,13]$. The apparatus used in these experiments is described in [12]. In general, to measure space charge profiles using the PEA technique a short high voltage pulse, typically less than $1 \mathrm{kV}$, is applied to the specimen; this may be in addition to any other voltage that is applied to the material. Isolated electric charges that are mechanically bound to the dielectric react to the electric field pulse by producing a mechanical force on the polymer that surrounds them. The mechanical force pulses exerted by the isolated bound charges cause acoustic wave pulses to travel through the dielectric at the speed of sound $(\sim 2000 \mathrm{~m} / \mathrm{s})$. A compression pulse will travel in one direction originating from the charge movement; a rarefaction will travel in the opposite direction. The directions depend on the relative direction of the pulse field and the charge polarity. The acoustic pulse is coupled to a piezoelectric sensor comprising a poled PVDF electret, which converts the received acoustic pulse into an electrical signal. The acoustic pulse originating from charges furthest from the microphone take longest to reach it and hence the voltage - time waveform from the microphone corresponds to a charge - distance profile within the specimen (after deconvolution and calibration). 


\subsection{Cailbration of technique with and without applied DC voltage}

In order to investigate the effects of the short high voltage electric field pulses on the XLPE specimens, we present the calibration of the PEA technique at low DC applied voltage on the XLPE specimen. An experiment was conducted using the PEA method with the following parameters:

- Electric field pulse amplitude: $400 \mathrm{~V}$

- Pulse repetition rate: 650 cycles/s

- Applied DC voltage: $1.8 \mathrm{kV}$

- Temperature of measurement: $20^{\circ} \mathrm{C}$

- Duration of experiment: 48 hours

Initially, the low DC electric field of $12 \mathrm{kV} / \mathrm{mm}$ (applied voltage of $1.8 \mathrm{kV}$ on $150 \mu \mathrm{m}$ ) was applied to the XLPE sheet specimen for less than 3 minutes. The applied DC voltage was immediately removed after that. Continuous PEA measurement was carried out for 48 hours at 10 minute intervals. Throughout the 48 hour experimental duration, the pulse generator operated at $650 \mathrm{~Hz}$ with amplitude of $400 \mathrm{~V}$. We would therefore expect the specimen to experience a great number, $\sim 10^{8}$, of high voltage pulses. The space charge profiles are shown in figure 1 . It can be seen that at time $\mathrm{T} 2 \sim 600$ s (with the DC applied voltage already removed), there is little space charge within the bulk of the material. Towards the end of the experiment ( 48 hours) at time T4, there is no significant build up of space charge within the bulk of the material although the specimen under test was subjected to enormous numbers of 
electric field pulses throughout the 48 hours. This shows that the PEA technique does not, itself, affect the space charge distribution with a sample.

\subsection{Measurement protocols}

In order to investigate the charge dynamics in the XLPE sheet specimens under high dc electric field, two different measurement protocols were used. Both experiments were conducted at a temperature of $20 \pm 0.1^{\circ} \mathrm{C}$. Prior to measurement, the XLPE sheet specimens were cleaned with isopropyl alcohol and allowed to dry. The first measurement procedure was to apply a dc electric field at $120 \mathrm{kV} / \mathrm{mm}$ for a period of 48 hours. PEA measurements were taken at 6 second intervals for the first 10 minutes and subsequently every 15 minutes. The second measurement procedure was aimed at determining the onset/threshold for charge packet generation. The sheet specimen was subjected to an applied field of $120 \mathrm{kV} / \mathrm{mm}$ for the duration of 1 hour until a charge packet was initiated. The applied electric field was then reduced to $90 \mathrm{kV} / \mathrm{mm}$ for 30 minutes and then further reduced to $80 \mathrm{kV} / \mathrm{mm}$ for an hour. At this point the applied field was increased to $90 \mathrm{kV} / \mathrm{mm}$ for another 1 hour and finally to 120 $\mathrm{kV} / \mathrm{mm}$ for another 1 hour. Throughout the second experiment the PEA measurements were taken at intervals of $6 \mathrm{~s}$ for about 10 minutes and then changed to 3 minutes intervals at each of the voltage levels applied. In all the measurement performed, the applied electric field pulse's amplitude was set at $400 \mathrm{~V}$ with repetition frequency of $\sim 800 \mathrm{~Hz}$.

\section{RESULTS}

\subsection{Measurement under constant dc electric field $(120 \mathrm{kV} / \mathrm{mm})$ and temperature $\left(20^{\circ} \mathrm{C}\right)$ for a duration of 48 hours}

Figure 2 shows the time-dependent space charge and electric field profiles as a function of distance through the specimen when the average applied electric field was $120 \mathrm{kV} / \mathrm{mm}$ (i.e. 
the applied dc voltage was $18 \mathrm{kV}$ ). This is shown in colour and as a moving image at the following web site: <include web site address here>. The negative and positive charge peaks at the cathode and anode correspond to the induced charges on the electrodes. These appear broad because of the limit of spatial resolution of the measurement system; in particular the thickness of the PVDF film used for the microphone.

During this period negative charge is injected from the cathode, after about $500 \mathrm{~s}$, and advances across the sample to build up the field at the anode. When the anode field reaches a value of about $140 \mathrm{kV} / \mathrm{mm}$, see figure 3 , a positive charge packet can be seen to just separate from the anode peak. This packet must be initiated at or close to the anode. This packet crosses the sample in about 9000s $(2.5 \mathrm{hrs})$ and as it exits at the cathode another positive packet is created near the anode. The process is repeated regularly over the subsequent period of 48 hours with diminishing packet amplitude, but unchanged transit time (see the arrows in figure 3).

As the positive charge packet crosses the sample the electric field at its front increases to about $170 \mathrm{kV} / \mathrm{mm}$, point ' $\mathrm{a}$ ' in figure 4 . The field at the anode initially drops but then starts to rise again as the packet approaches the cathode. When the packet exits at the cathode, the anode peak is enhanced to $210 \mathrm{kV} / \mathrm{mm}$, see figure 3 (arrow) and 4 and a new packet is initiated. The maximum charge density in the second packet was lower than that in the first packet despite the fact that the anode field at initiation was substantially greater, namely 210 $\mathrm{kV} / \mathrm{mm}$ as compared to $140 \mathrm{kV} / \mathrm{mm}$, see figures 3 , and 4 . The packet generation process was repeated with the maximum charge density in the packet decreasing continually until the anode field on the exit of the packet dropped to around $140 \mathrm{kV} / \mathrm{mm}$ at about $128000 \mathrm{~s}$, see

figure 3. At this time some very weak positive charge peaks $\left(<5 \mathrm{Cm}^{-3}\right)$ could just be discerned moving against a background of negative space charge. When detected they were in the middle of the sample, however, the negative space charge is largest close to the anode 
$\left(\sim 20-25 \mathrm{Cm}^{-3}\right)$ and they may have been too small to be detected in that region, see figure 5 . These weak packets $\left(<10 \mathrm{Cm}^{-3}\right)$ continue until the applied voltage is switched off and lead to the irregular fluctuations of the anode field, see figure 4, which intermittently rises to 140 $\mathrm{kV} / \mathrm{mm}$ and then drops again. When the voltage is switched off the sample can be seen to contain both positive and negative heterocharge at the electrodes see figure 5.

\subsection{Measurement under dc electric field stepped between $80 \mathrm{kV} / \mathrm{mm}$ and $120 \mathrm{kV} / \mathrm{mm}$.}

As previously found in the constant applied field case, negative charge is injected at the cathode and moves across the sample to the anode, where it causes the anode field to be enhanced sufficiently to initiate a positive charge packet, see figure 6 . In this case the anode field reached a value of $165 \mathrm{kV} / \mathrm{mm}$ before a positive packet separated from the anode peak. This field is higher than that observed for the first peak in the previous experiment. However, as the packet moves away from the anode the field at the front of the packet is reduced to 135 $\mathrm{kV} / \mathrm{mm}$ and the anode field to $100 \mathrm{kV} / \mathrm{mm}$.

At this point, i.e. after 3600 s ( 1 hour), the applied field is reduced to $90 \mathrm{kV} / \mathrm{mm}$ (voltage reduced from $18 \mathrm{kV}$ to $13.5 \mathrm{kV}$ ), which was maintained for $1800 \mathrm{~s}$. The space charge profiles observed are presented in figure 7. It can be seen that the packet continues to move across the sample, but with diminishing amplitude, such that after 30 minutes it is hardly detectable. As the packet moves the field at its front decreases to $90 \mathrm{kV} / \mathrm{mm}$, and the anode field builds up from $55 \mathrm{kV} / \mathrm{mm}$ to $95 \mathrm{kV} / \mathrm{mm}$. At this point the applied field is further reduced to 80 $\mathrm{kV} / \mathrm{mm}$. The small amount of positive charge left by the packet disappears leaving a region of negative space charge peaked at the anode, see figure 8 . During this time the anode field remains essentially unchanged at $85 \mathrm{kV} / \mathrm{mm}$. An increase of the applied field to $90 \mathrm{kV} / \mathrm{mm}$ returns the anode field to $95 \mathrm{kV} / \mathrm{mm}$ but does not lead to a change in space charge profile or the initiation of a charge packet over a period of 1 hour, see figure 9 . A further increase to an applied electric field of $120 \mathrm{kV} / \mathrm{mm}$ led to a slight build-up of negative space charge at the 
anode over a period of 1 hour, see figure 9. This was sufficient to raise the anode field to 135 $\mathrm{kV} / \mathrm{mm}$, but did not initiate a charge packet.

\section{DISCUSSION}

The results presented clearly demonstrate the need for an onset or threshold field if the charge packets are to be initiated. In the first experiment it was shown that packets were continually generated as long as the anode field reached $140 \mathrm{kV} / \mathrm{mm}$. The second experiment showed that a packet could not be initiated when the anode field only reached $135 \mathrm{kV} / \mathrm{mm}$ on reapplication of an applied field of $120 \mathrm{kV} / \mathrm{mm}$. If the packet is caused by ionic dissociation and transport of one of the ionic species to the cathode where it is neutralised it could be argued that the failure to initiate a packet might be due to exhaustion of the dissociable species in the region of the anode. In the first experiment, however, we were able to initiate several packets with a magnitude decreasing from 50 to $25 \mathrm{Cm}^{-3}$, but only one packet of magnitude $35 \mathrm{Cm}^{-3}$ in the second experiment. Exhaustion of the positive charge reservoir is therefore unlikely to be the explanation for the failure to generate further packets. Hence there must be a packet initiation field lying between $135 \mathrm{kV} / \mathrm{mm}$ and $140 \mathrm{kV} / \mathrm{mm}$ for the type of packets observed here. This result is consistent with all three current theories. In [6] a threshold field was required for a switch to a high injection current, in [5] it is required to initiate carrier generation and in [8] it is required to create trapped carriers some fraction of which become mobile. The value of threshold field observed in the present experiments is lower that those reported previously $[5,6,8]$, but not severely so. In our case the threshold field is the minimum packet onset field obtained over experiments lasting up to 48 hours during which the onset field steadily declined from a high of $210 \mathrm{kV} / \mathrm{mm}$ down to 140 $\mathrm{kV} / \mathrm{mm}$. It is noticeable that the experimental onset fields reported in [7] diminish over a period of $4800 \mathrm{~s}$ ( 80 minutes) from $250 \mathrm{kV} / \mathrm{mm}$ to around $170 \mathrm{kV} / \mathrm{mm}$, and it may be that a longer experiment would see them approach our lower value.

In our work the charge packets are triggered by the formation of a hetero-charge (negative space charge) field at the anode. A mechanism such as this is a feature in all the three 
models. In [6] field enhancement is required at the electrode. In [8] a bipolar charge injection allows the maximum field enhancement to occur in the body of the sample, where the positive and negative charge fronts meet, and generate the packet there. In our case charge injection consists mainly of negative charge from the cathode, which moves slowly to accumulate at the anode that must be substantially blocking to negative charge. The absence of a substantial positive charge injection means that the highest field during this period is at the anode, and this does not reach a packet generating level until sufficient negative charge has crossed the sample. In our case this takes a considerably longer time than in the previously reported work, because the negative charge moves slowly. There is evidence (to be reported elsewhere) that this charge is deep trapped $(\sim 1 \mathrm{eV})$ and moves by field-assisted hopping (see chapter 9 of [14]) which would be consistent with a long transit time for the negative space charge and probably also with a very slow rate for extraction at the anode. Only in one of the models [8] is the extraction rate considered. In this model the anode field and the barrier height are the important factors. It is noticeable that the anode field drops substantially as the positive packet starts to move (see figure 4) and hence negative charge extraction at this time will be reduced allowing the negative space charge to build up.

As the first positive packet exits at the cathode the anode field builds up to a value far in excess of the field that initiated the packet. The reason is that the negative charge concentration at the anode has increased by almost the same amount as the maximum charge density in the packet. Of course, this increase could be the result of the increased cathode injection as the packet approaches the cathode and it can be observed for some of the later packets in the sequence just before the packet reaches the cathode. Much of such injected charge will be used to neutralise the packet, and will not be available for transport to the anode. In addition we would expect the amount of injected charge to depend on the cathode field. As can be seen in figure 3, this shows no systematic change over the sequence. Therefore negative charge injection is unlikely to be responsible for the changes in anode field brought about by the negative hetero-charge region.

The total charge in the sample during the packet formation sequence is plotted as charge per unit area of sample $\left(\mathrm{Cm}^{-2}\right)$ versus time (s) in Figure 10. In one of the models, Hozumi et al 
[6] suggested that the positive charge packet is caused by charge injection from the anode. In another model [5], it is suggested that packet generation is caused by field-induced dissociation as a source of carriers. Analysis of our experimental data was compared with these models.

If the positive charge packet generation is caused by charge injection and it is assumed that the packet is composed of mobile excess positive charges $\left(+\mathrm{Q}_{\text {packet }}\right)$ superimposed upon a background of stationary negative charge $\left(-Q_{\text {negative }}\right)$, the residual negative charge after

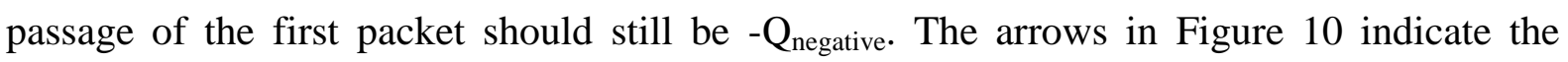
steady decrease in magnitude of the net negative charge after the exit of positive charge packets; this model [6] is therefore not appropriate to our findings.

If the charge packet generation is caused by field-induced dissociation [5], such a process would result in the formation of charges that would be equal in magnitude and opposite in polarity (e.g. $+Q_{\text {packet }}$ and $-Q_{\text {species }}$ ). In this second scenario, it is again assumed that the positive charge packet that transits the sample is superimposed upon a background of stationary negative charge (-Q $\left.\mathrm{Q}_{\text {negative }}\right)$, When the positive charge packet leaves the sample, the residual net charge in the sample should be $-\mathrm{Q}_{\text {species }}-\mathrm{Q}_{\text {negative }}$ although some of the negative charges may exit through the anode during the increase in the local field there. From Figure 10 , the net negative charge to start with before the first positive charge packet is about $0.001 \mathrm{Cm}^{-2}$. After the exit of the first positive charge packet, the magnitude of residual net negative charge is about $\sim 0.0042 \mathrm{Cm}^{-2}\left(-\mathrm{Q}_{\text {species }}-\mathrm{Q}_{\text {negative }}\right)$. In this case, the negative dissociated species left behind in the sample having the same magnitude as the positive charge packet should be $0.0032 \mathrm{Cm}^{-2}$. With the assumption that the positive charge packet is superimposed on a background of stationary negative charge, the net positive charge should be $\sim 0.0022 \mathrm{Cm}^{-2}$. The measured value is about $\sim 0.0017 \mathrm{Cm}^{-2}$ (indicated in Figure 10 as ' $\mathrm{B}$ '). The near equivalence of the estimated and measured values indicates that the first packet is formed by field-dissociation, with most of the negative charge produced remaining close to the anode where it can only be slowly extracted or neutralized. 
Because of the initiating anode field at the time of the second packet is greater than that for the first packet we would expect a charge packet with greater density. Instead we find that the second charge packet has a smaller charge density. The explanation could be that this and succeeding charge packets are created by charge injection and we only see the charge packet against the background of a negative space charge region around the anode. Part of the positive charge density in the packet is balanced by the existing negative charge and we only see the net positive charge. The real packet density would be much higher as expected from the higher generation field. This explanation is consistent with the increase in the packet charge density as it transits the sample towards the cathode and enters a region of lower negative charge density. The same results could, however, be explained if the packet is created by field ionisation. In this case the high field at the anode that causes field ionisation also allows the extraction of the negative charge created to be ejected or injects positive charge to neutralise it. Again as the packet transits the sample we see its magnitude against the background of the negative charge density in the region it occupies. During transit the anode field drops and the extraction/neutralisation rate is correspondingly much reduced and the negative heterocharge at the anode now remains at substantially the same level as created after the first packet. This would argue for an extraction/neutralisation rate dependent upon the hetero-charge concentration as well as the local field. There is in fact evidence for positive charge injection through the electro-luminescence observed when the applied field exceeds $70 \mathrm{kV} / \mathrm{mm}$ [9], which has been assigned to charge recombination. In our experiments it appears that positive injection just exceeds the negative charge density produced by dissociation, and consequently the anode field on packet exit decreases slightly with each succeeding packet. Eventually the packets become very weak with a front edge field that almost oscillates. These packets cannot be seen against the negative charge background until the middle of the sample where they are apparently generated. At this point the recorded negative charge density at the anode becomes almost constant at $\sim 14 \mathrm{Cm}^{-3}$, and thus the packets must be only about $1-5 \mathrm{Cm}^{-3}$, or less. The presence of the positive charge can be more clearly seen when the voltage is switched off. Then it is found that the negative charge at the anode initially increases to about $20 \mathrm{Cm}^{-3}$, and there is a similar positive charge accumulation at the cathode. 
The sequence of events described above seems to be more complex than that envisaged in current models. The advent of the first packet and the subsequent increase in anode field argue for field dissociation as the mechanism. A packet composed of an excess of mobile positive carriers would be expected to spread out due to the difference between the high field at its front and the low field at its rear, see figure 4 . The fact that the packet does not appear to spread out indicates that is unlikely to be composed of an excess of mobile positive carriers. Instead it may be an ionisation front in which the mobile negative charge moves to the anode, and consequently the positive ionisation front moves towards the cathode, as suggested in [8]. However, unlike the model of [8] the negative charge can only be neutralised very slowly at the anode for the first packet. Another factor that argues for the ionisation front mechanism is the periodic generation of packets. This feature could not be reproduced by either of the other two models $[5,6]$. However these two models did not allow for negative charge to build up at the anode, requiring immediate extraction instead. If space charge build up were allowed by slow extraction repetitive generation may become possible in these models. On subsequent packet-generation the slowly reducing negative charge density at the anode, suggests that anode injection is now effectively neutralising slightly more than the negative charge produced by the dissociation generating the packet. Consequently successive packets decay in amplitude. In fact this sequence is similar to the experimental results reported in [7]. A further point to note is that the step-change experiment shows that the packet once formed can retain its integrity as a packet, but with a reduced magnitude, even when the field at its front drops to $100 \mathrm{kV} / \mathrm{mm}$. This could argue for an explanation in terms of a field ionisation front with a two-step mechanism for carrier generation as in [8]. In our case the mobile carriers generated would be negative carriers rather than holes as in [8]. A mechanism involving a distributed threshold for carrier generation is unlikely because of the sharp boundary between anode fields that generate packets $(>140 \mathrm{kV} / \mathrm{mm})$ and anode fields that do not generate packets $(135 \mathrm{kV} / \mathrm{mm})$. An alternative explanation is that field-ionisation can occur for fields in excess of $100 \mathrm{kV} / \mathrm{mm}$, but that the negative carriers do not move fast enough at these fields to prevent recombination. Only when the field reaches $140 \mathrm{kV} / \mathrm{mm}$ can the negative carriers displace before recombination occurs giving rise to the positive ionisation front which then advances in the form of a packet. In this case the slow displacement of the negative charge will have a strong influence upon the speed at which the positive packet transits the sample. The fact that 
the packets do not spread out, and are repetitively produced, together with the compensating negative charge observed for the first packet indicate that the basic mechanism may well be that described by the model of [8]. Some modifications would however be required to fit the present results, most notably a large barrier or an onset field for negative charge extraction/positive charge injection at the anode, and a very high barrier for the fielddependent mobility of the negative carriers.

There is also the question as to the nature of the charge carriers. The samples used had undergone a 48 -hour heat treatment at $50{ }^{\circ} \mathrm{C}$ prior to use. This thermal conditioning treatment removes much of the volatile material and certainly reduces the acetophenone concentration [10]. It does not, however, remove it completely, and as pointed out in [5] the treatment may well have caused a reaction with anti-oxidant in the material leading to a dissociable chemical species. It may be possible that this species is responsible for the charge generation observed here as the transit times are similar to those found in [5]. It is interesting to note that antioxidant clusters can cause oxidation $[15,16]$. Such clusters may be produced if acetophenone solvated the anti-oxidant at high temperature and allowed it to associate. A clearer idea of their nature will depend on a spectral analysis of the electro-luminescence produced during charge packet transit.

The above considerations lead us to suggest that the charge packets formed during the first phase of the process (i.e. up to about $68000 \mathrm{~s} \approx 19$ hours) are produced by field ionisation of an unknown chemical species. The onset field is required to both ionise the species and to displace the mobile negative charge and hence prevent recombination without packet formation. The packet advances as a progressive field ionisation revealed by displacement of the negative charge to the rear of the packet where it recombines. At times longer than 68000s, a nearly steady state of packet generation occurs. The period of the field oscillations remains the same, so it seems that this also involves packet formation and transit of the sample, although their magnitude is much reduced. Beyond 128000s $(\approx 36$ hours $)$ there are intermittent fluctuations in the local field that appear to be associated with charge displacement, but we have insufficient resolution to say whether or not this involves packets of charge. 


\section{CONCLUSIONS}

A critical onset field is required before the generation of charge packets that in the present case has a value of $140 \mathrm{kV} / \mathrm{mm}$.

The positive charge packets are formed at or near the anode because they rely on the build-up of a negative hetero-charge field to reach the required onset field. Because the transport of the negative space charge is very slow the time before the first packet is initiated is of the order of hours. Injection of positive space charge is attested by the presence of electroluminescence but the positive space charge moves even slower than the negative charge and its injection is very weak. For this reason charge packets cannot develop in the middle of the sample such as occurs in the model of [8], and the experiments of [7].

The first charge packet at least is caused by a moving front of field ionisation as shown by the equivalent increase in negative hetero-charge at the anode. The inability of the negative charge to exit quickly at the anode, unlike the situation considered in [8] prevents the exact repetition of the process for succeeding packets. The subsequent generation of packets is governed by the anode field as determined by the balance of negative charge extraction/positive charge injection processes and field ionisation. Consequently the amplitudes of successive packets reduce, to the point at which a nearly exact repetition can be achieved.

The slow movement of the negative charge created by field ionisation is responsible for the slow movement of the packet. This must mean that recombination of the field ionised charges is a slow process. The 'mobile' negative charges cannot therefore be electrons in a conduction band. Other work indicates that the negative space charge is built up by fieldassisted electron hopping between centres about $1 \mathrm{~nm}$ apart. The field difference between the front of the packet and its rear would allow a relatively quick displacement of negative charge towards the anode, that would separate mobile charge from the ionisation front and 
hinder recombination. Behind the packet, however, the movement of negative charge would be much slower. As yet it is unclear what the ionised species are.

The packet can continue to travel at fields down to $100 \mathrm{kV} / \mathrm{mm}$ albeit at a lower magnitude until eventually it disappears. A possible explanation for this is that the field at the packet front is high enough for field ionisation but that the displacement of the mobile charge which is exponentially dependent upon the local field becomes small allowing substantial recombination leading to packet extinction at a field between 90 and $80 \mathrm{kV} / \mathrm{mm}$.

\section{ACKNOWLEDGMENTS}

We would like to acknowledge K. Kaneko, Y. Suzuoki and T. Okamoto for their useful discussions in this paper. The University Of Leicester's assistance is acknowledged in providing study leave for L.A. Dissado and J.C. Fothergill and a fee waiver scholarship for Alex See. 


\section{REFERENCES}

1. A. Tanaka, M. Maeda and T. Takada, "Observation of Charge Behaviour in Organic Photoconductor using Pressure-wave Propagation Method", IEEE Trans. on DEI, Vol. 27, No 3, pp. 440-444 (1992)

2. O Fanjeau, D Mary and D Malec, "A note on charge recombination in low density PE under a moderate ac 50Hz field”, J. Phys. D applied phys 33, pp 61-64, (2000)

3. A Cherifi, M. Abou Dakka and A. Toureille, "The Validation of the Thermal Step Method” IEEE Trans. on DEI, Vol. 27, No. 6, pp. 1152-1158 (1992)

4. R. Liu, T. Takada and N. Takasu, "Pulsed Electro-acoustic Method for Measurement of Charge Distribution in Power Cables under both DC and AC Electric Fields", J. Phys. D Appl. Phys. Vol.26, pp.986-993 (1993)

5. N. Hozumi, T. Takada, H. Suzuki and T. Okamoto, "Space charge behaviour in XLPE cable insulation under 0.2 - 1.2MV/cm dc fields", IEEE Trans. on DEI, Vol. 5, No. 1, pp. 8290 (1998)

6. N. Hozumi H. Suzuki, T. Okamato, K. Watanabe and A. Watanabe, " Direct observation of time dependent space charge profiles in XLPE cable under high electric fields", IEEE Trans. on DEI, Vol. 1, No. 6, pp. 1068-1076 (1994) 
See, Dissado and Fothergill

$9 / 16 / 08$

2:31 PM

7. H. Kon, Y. Suzuoki, T. Mizutani, M. Ieda and N. Yoshifuji, " Packet-like space charge and conduction current in Polyethylene cable insulation", IEEE Trans. on DEI, Vol. 3, No. 3, pp. 380-385 (1996)

8. K. Kaneko, T. Mizutani and Y. Suzuoki, "Computer simulation on formation of space charge packets in XLPE films", IEEE Trans. on DEI, Vol. 6, No. 2, pp. 152-158 (1999)

9. C. Laurent, G. Teyysedre, J.L. Auge, G. Mazzanti, G.C. Montanari, L.A. Dissado, J.C. Fothergill and A. See "Space charge and associated electroluminescence processes in XLPE cable peelings", Ann. Rep.CEIDP, IEEE Conf. Pub. 00CH37132 pp.568-572， (2000)

10. L.A. Dissado, J.C. Fothergill and A. See, G. Stevens, L. Markey, C. Laurent, G. Teyssedre, U.H. Nilsson, G. Platbrood and G.C. Montanari, "Characterising High-Voltage XLPE cables by electrical, chemical and microstructural measurements performed on cable peelings: the effects of surface roughness, thermal treatment and peeling location”, Ann. Rep CEIDP, (IEEE Conf. Pub. 00CH37132) pp.136-140, (2000)

11. J.M. Alison, "A high field pulsed electro-acoustic apparatus for space charge and external circuit current measurement within solid insulators ”, J. Meas. Sci. \& Technol. vol. 9 pp. 1737-1750, (1998).

12. J.C. Fothergill, L.A. Dissado, J.M. Alison and A. See "Advanced Pulsed Electro-Acoustic system for Space charge measurement", IEE. Proc. DMMA, Conf. Pub. No. 473. pp. 352356, (2000) 
13. T. Takada, "Acoustic and Optical methods for measuring electric charge distributions in dielectrics”, IEEE Trans. DEI, Vol. 6, No. 5, pp519-547, (1999)

14. L.A. Dissado and J.C. Fothergill, Electrical Degradation and Breakdown in Polymers (P.Peregrinus for IEE, London 1992)

15. B.S.Bernstein IEEE Int.Symp.Elect.Insul. (Montreal), 11-21, (1984)

16. R.B.Walter and J.F.Johnson, J. Polym. Sci. Mocrolmol. Rev., Vol. 15, 29-53, (1980) 


\section{List of Figure Captions}

Figure 1. Time-dependent space charge profiles in a $150 \mu \mathrm{m}$ thick XLPE sheet specimen when the applied electric field was $12 \mathrm{kV} / \mathrm{mm}$ (applied voltage at $1.8 \mathrm{kV}$ ) for $\sim 3$ minutes. The voltage was removed and PEA measurement was carried out for up to 48 hours. No significant space charge was observed even with the electric field pulse applied continuously (Pulse amplitude of $400 \mathrm{~V}$ and repetition rate at $650 \mathrm{~Hz}$ ).

Figure 2. Time-dependent space charge profiles in a $150 \mu \mathrm{m}$ thick XLPE sheet specimen when the applied electric field was $120 \mathrm{kV} / \mathrm{mm}$. The arrows indicate the direction of packetcharge movement. Time T1 at 588s, T2 at 12342s, T3 at 14142s and T4 at 19542s

Figure 3. Comparison of the temporal change of local internal electric fields at the anode and cathode sides. Average applied electric field was $120 \mathrm{kV} / \mathrm{mm}$.

Figure 4. Temporal change of local internal electric fields at the front, back of the charge packets together with the anode field. Average applied electric field was $120 \mathrm{kV} / \mathrm{mm}$.

Figure 5. Weak positive packets near the cathode and negative space charge accumulated near the anode at time T6 165342s. Voltage switched off and the sample can be seen to contain both positive and negative heterocharge at the electrodes. 
Figure 6. Space charge profiles measured during 1 hour of poling at $120 \mathrm{kV} / \mathrm{mm}$. (a) and (b) show the space charge and the internal electric field profiles respectively. Negative charge can be first observed to move from the cathode to the anode. Time T1 at $41 \mathrm{~s}, \mathrm{~T} 2$ at $1435 \mathrm{~s}$ and T3 at 3321s. The positive charge packet was initiated at about 3500s.

Figure 7. Space charge profiles at applied field of $90 \mathrm{kV} / \mathrm{mm}(13.5 \mathrm{kV}$ on $150 \mu \mathrm{m})$ for $1800 \mathrm{~s}$. (a) and (b) show the space charge and the internal electric field profiles respectively. The direction of the positive charge packet movement is from the anode to the cathode. Time T1 at $81 \mathrm{~s}$, time $\mathrm{T} 2$ at $810 \mathrm{~s}$ and time T3 at $1620 \mathrm{~s}$.

Figure 8 . Space charge profile at applied field of $80 \mathrm{kV} / \mathrm{mm}(12 \mathrm{kV}$ on $150 \mu \mathrm{m})$. (a) and (b) show the space charge and the internal electric field profiles respectively. Time T1 at 180s and $\mathrm{T} 2$ at $3600 \mathrm{~s}$.

Figure 9 (a) and (b) show the space charge and internal electric field profiles respectively, measured after 1 hour at $90 \mathrm{kV} / \mathrm{mm}$ and after 1 hour at $120 \mathrm{kV} / \mathrm{mm}$. Time T1 and T2 are at 3420 s

Figure 10. Showing the total net charge within the sample versus time. The arrows indicate the steady decrease in magnitude of the net negative charge after the exit of subsequent positive charge packets. The point marked ' $\mathrm{B}$ ' indicates the initiation of the first positive charge packet sequence. 


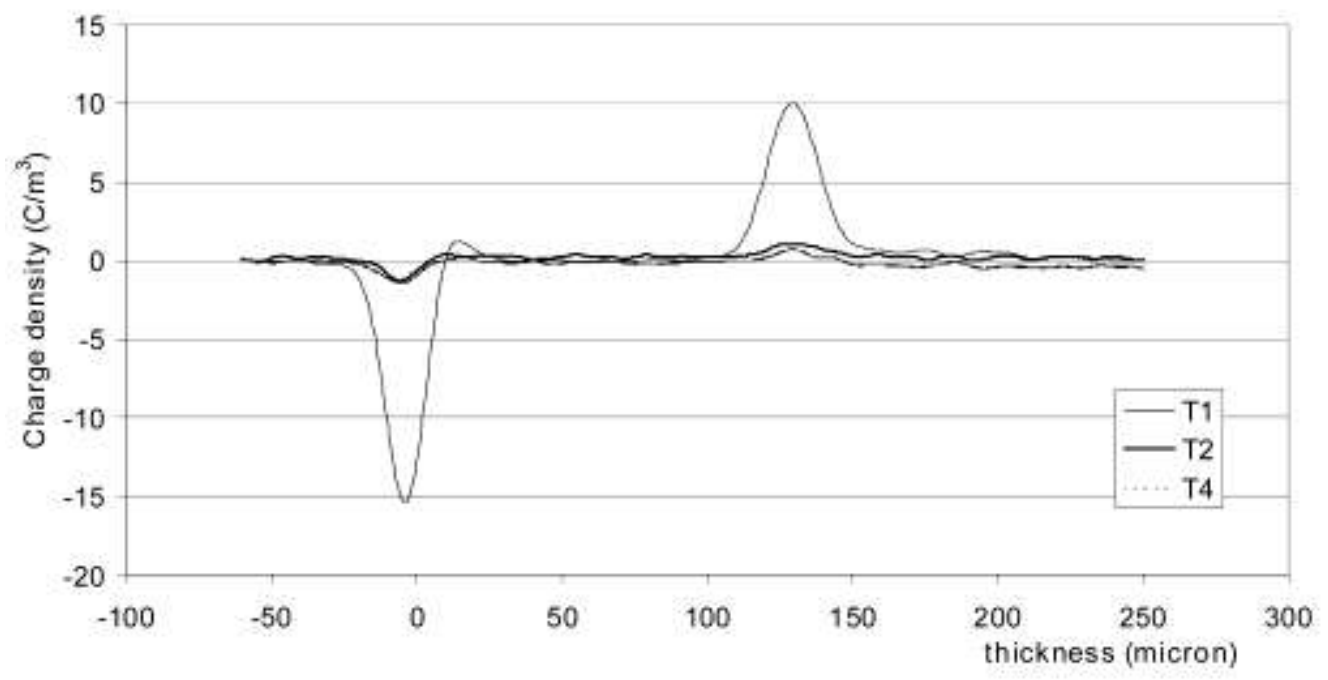

Figure 1 


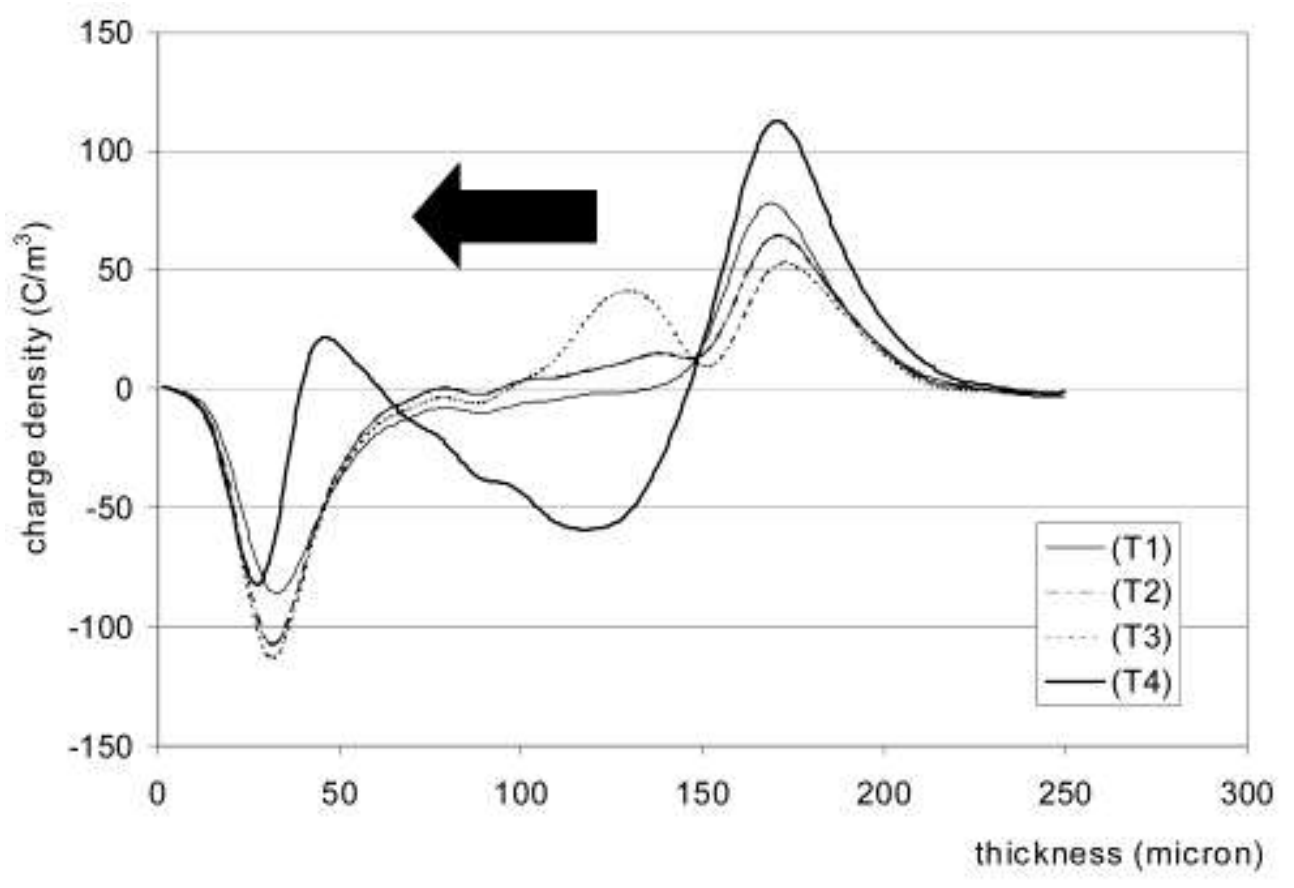

Figure 2 


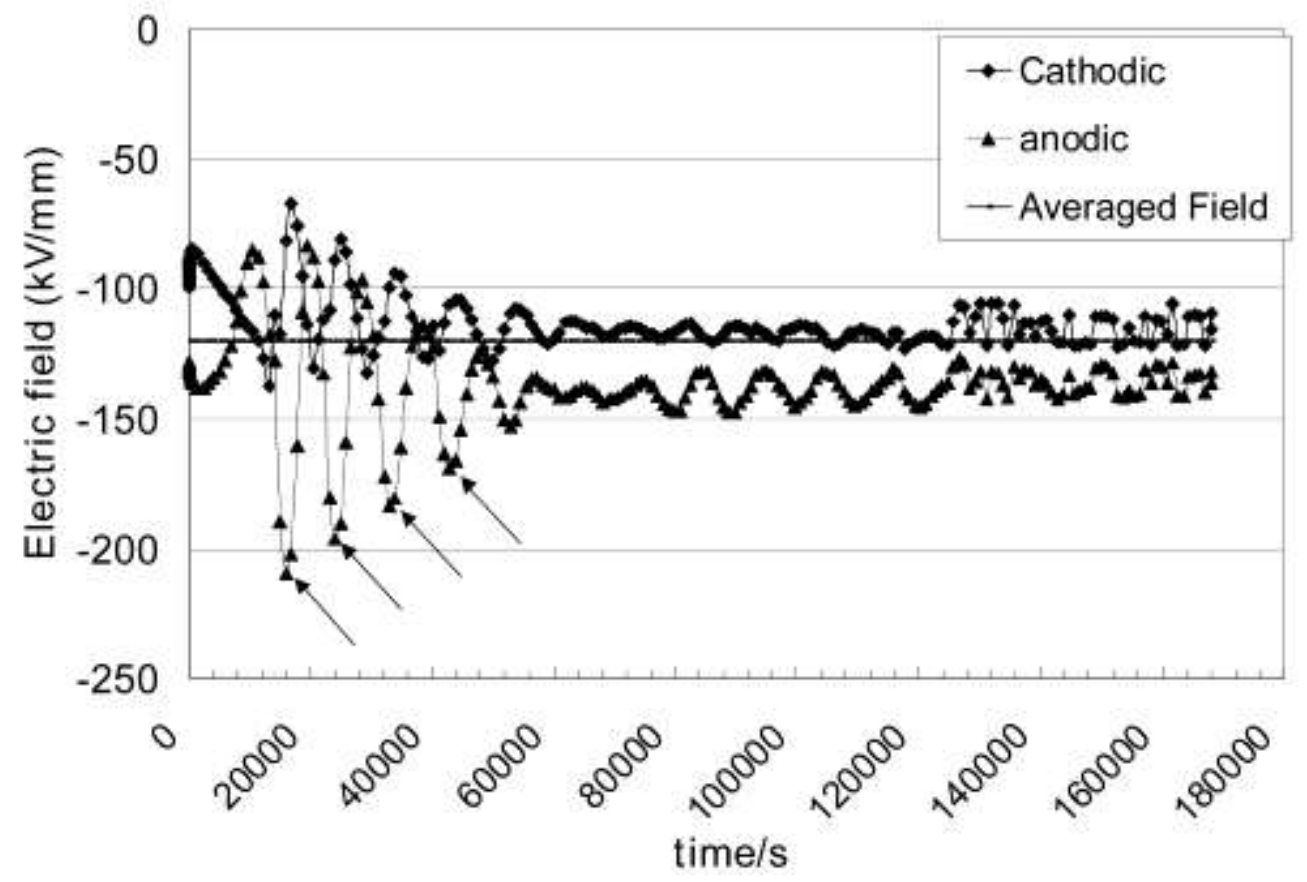

Figure 3 


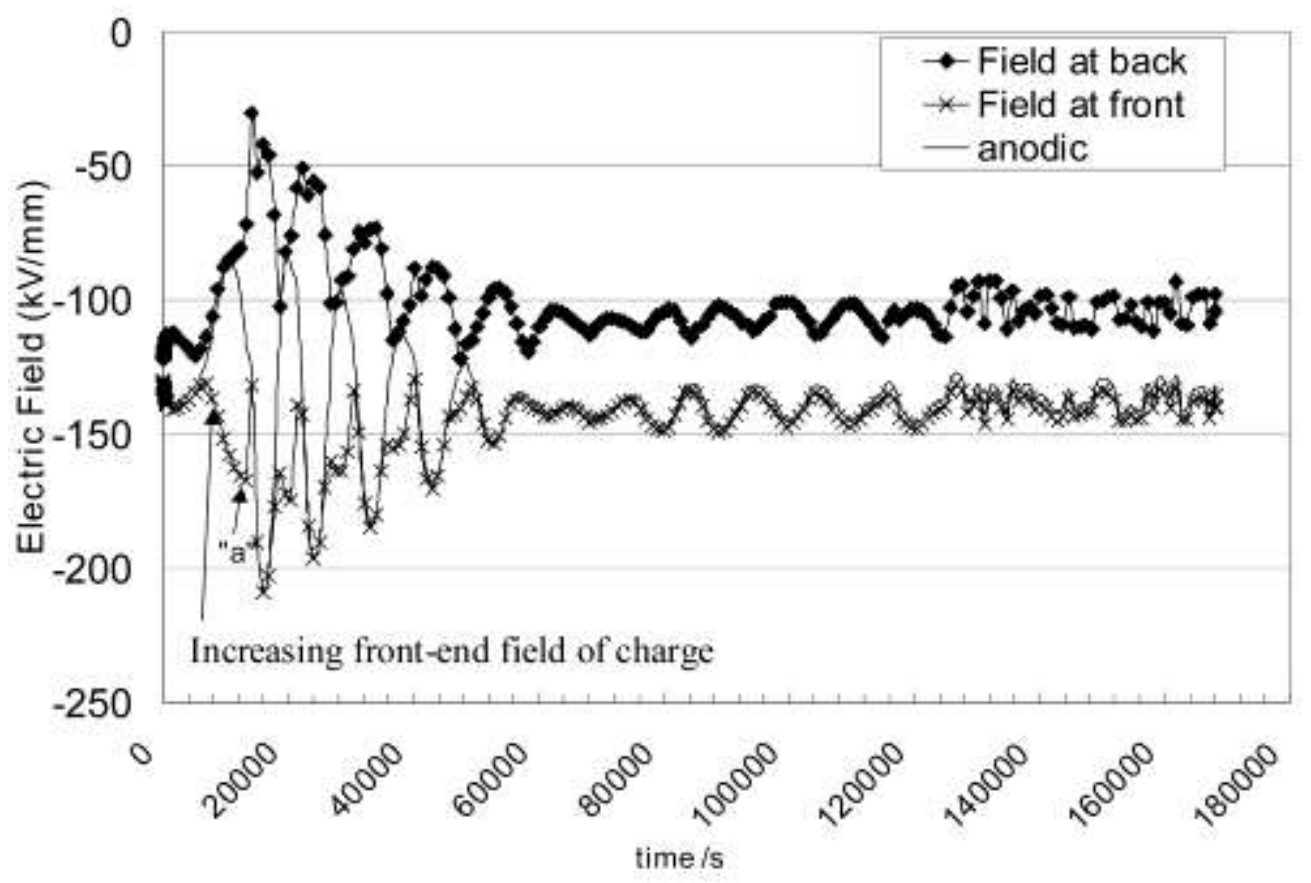

Figure 4 


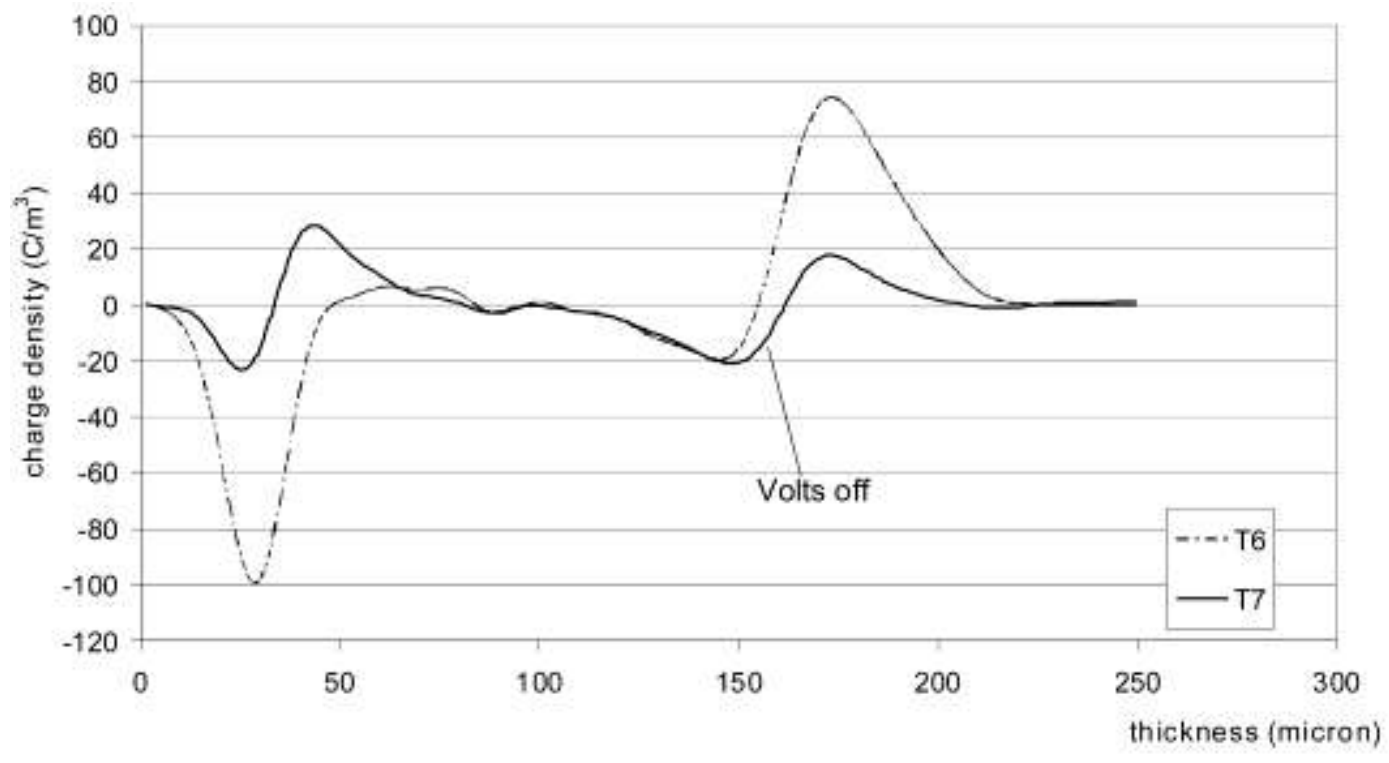

Figure 5 


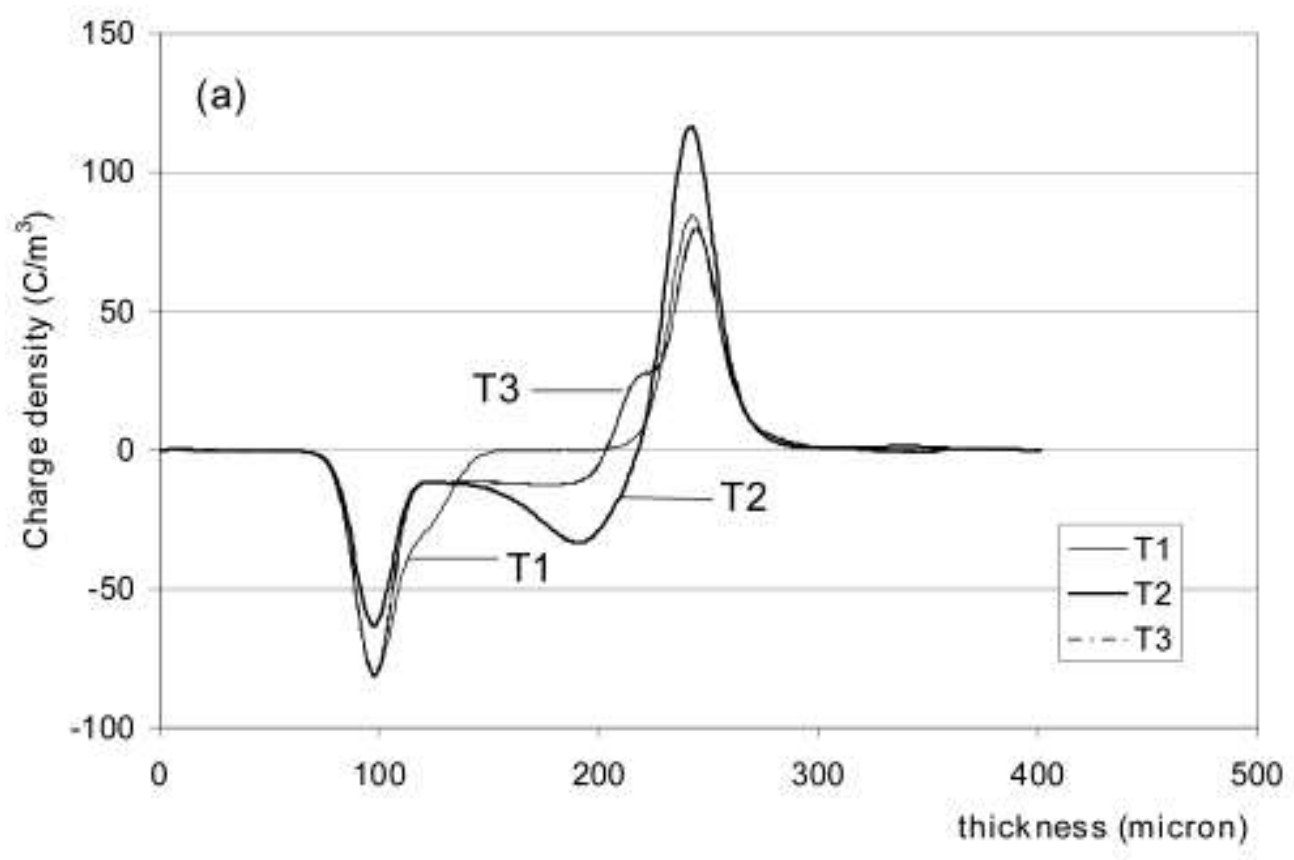

Figure 6a 


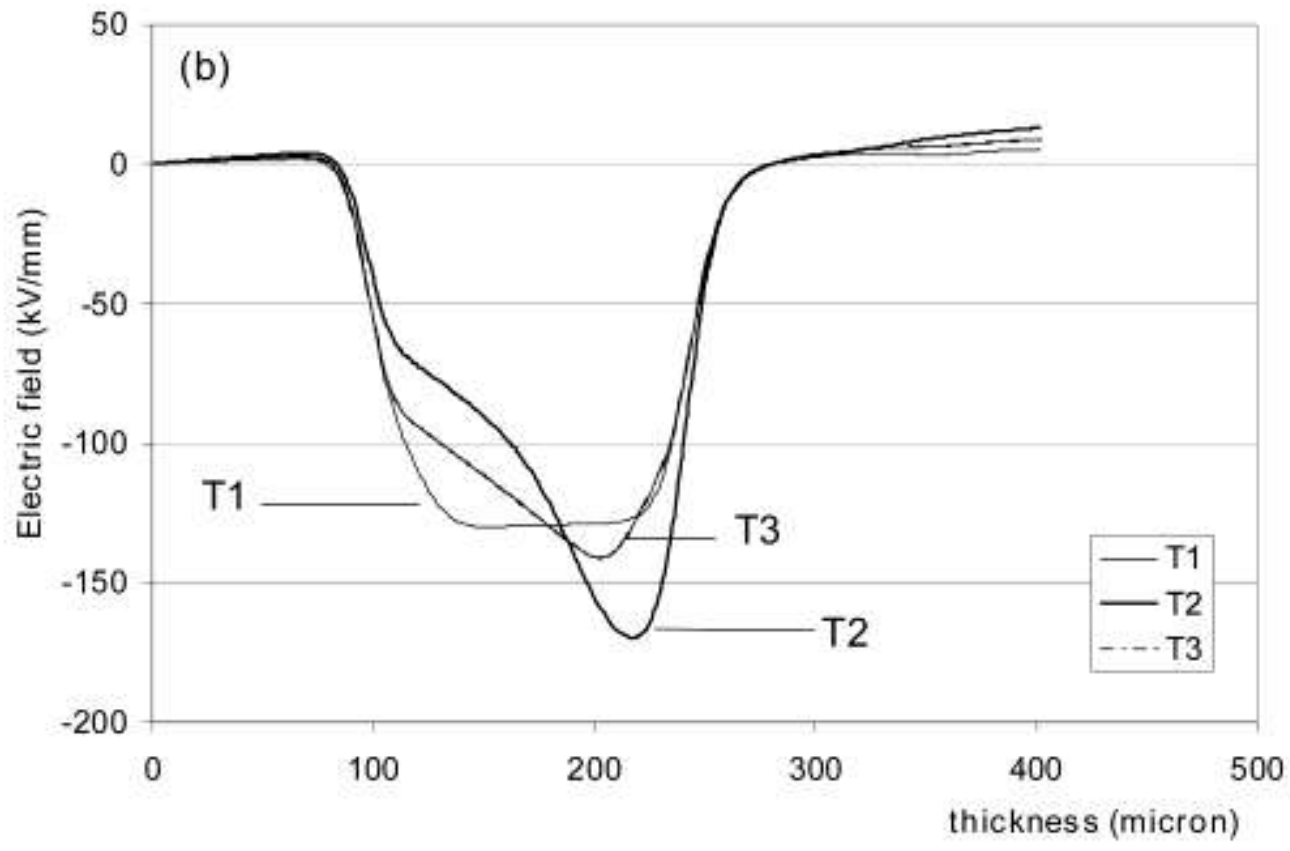

Figure $6 b$ 


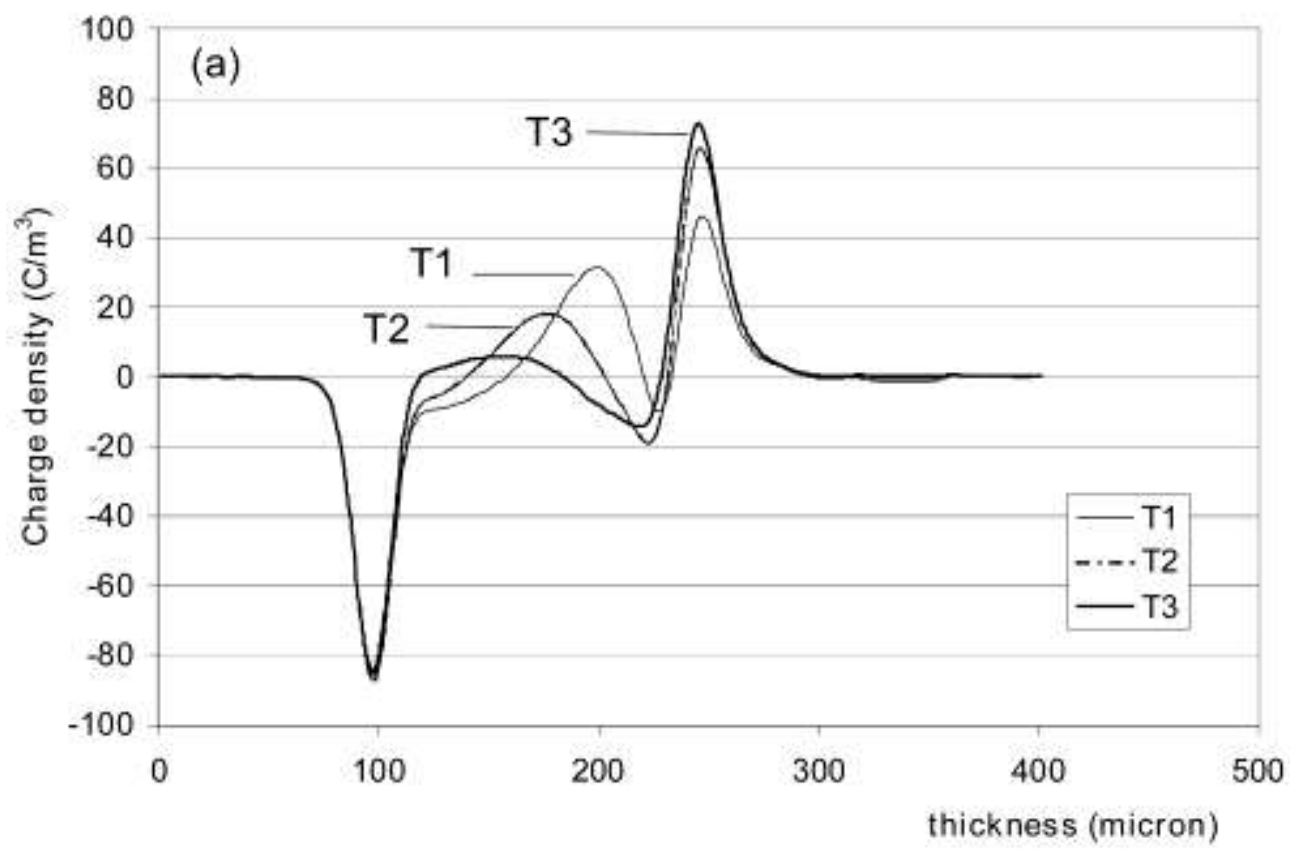

Figure 7a 


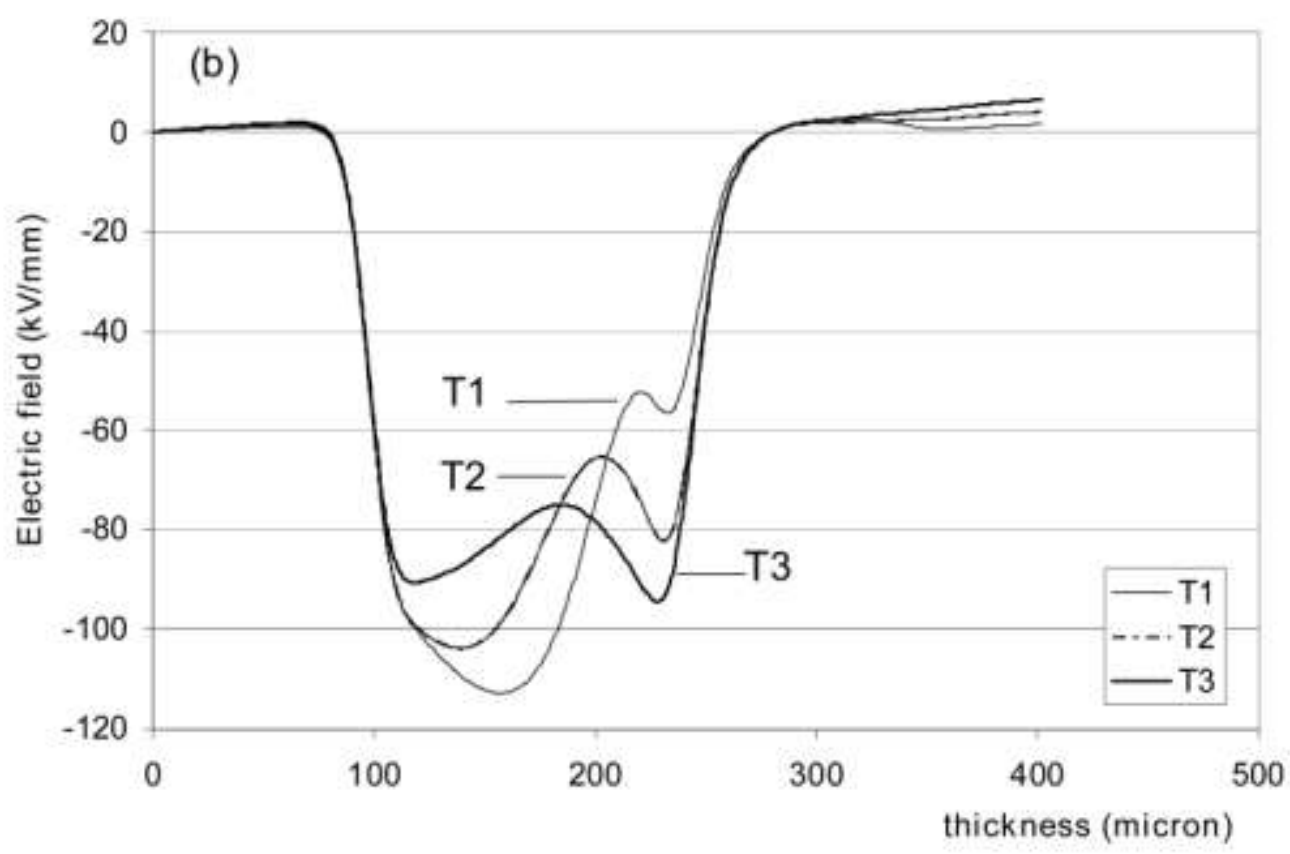

Figure $7 b$ 


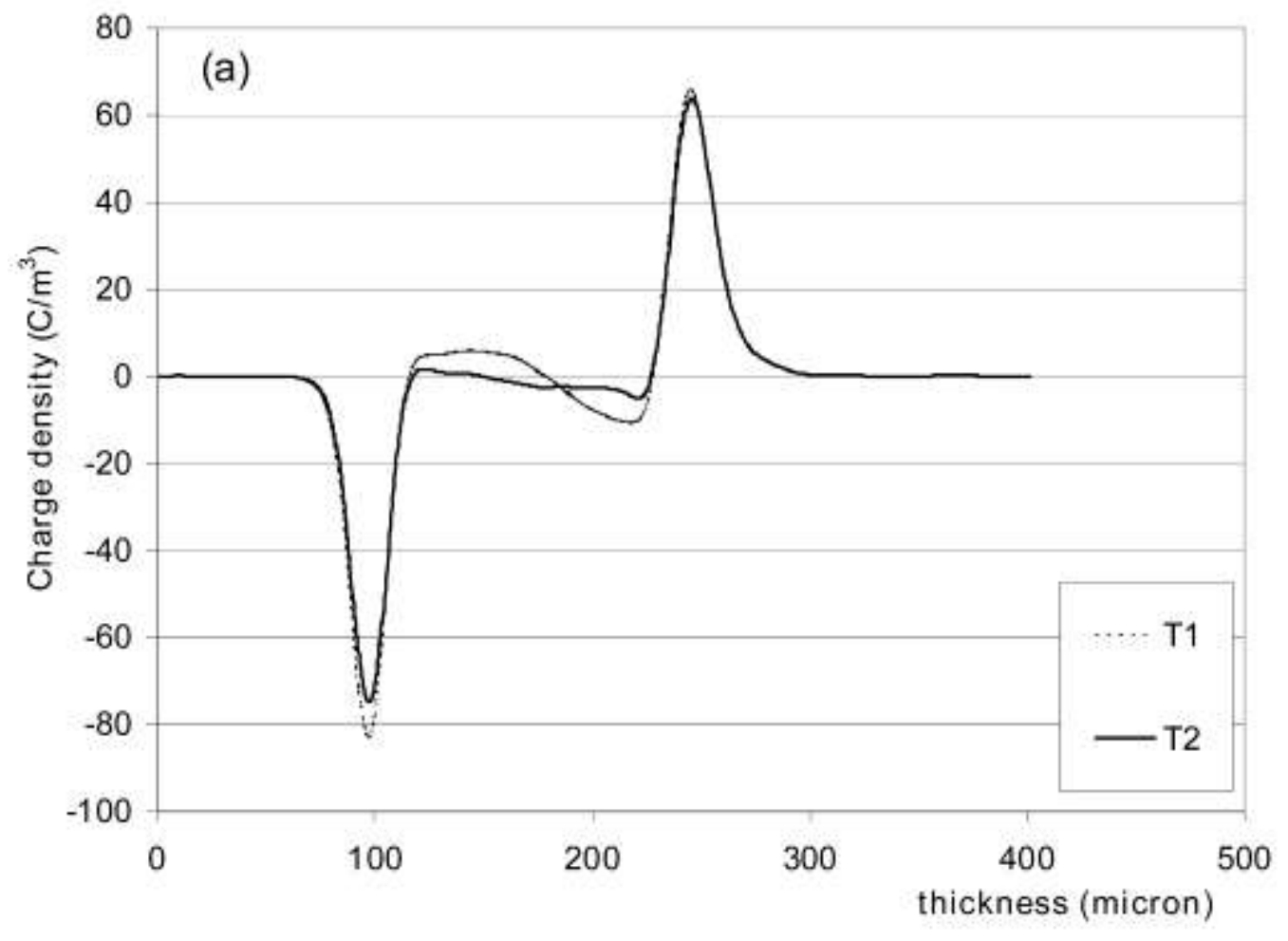

Figure 8a 


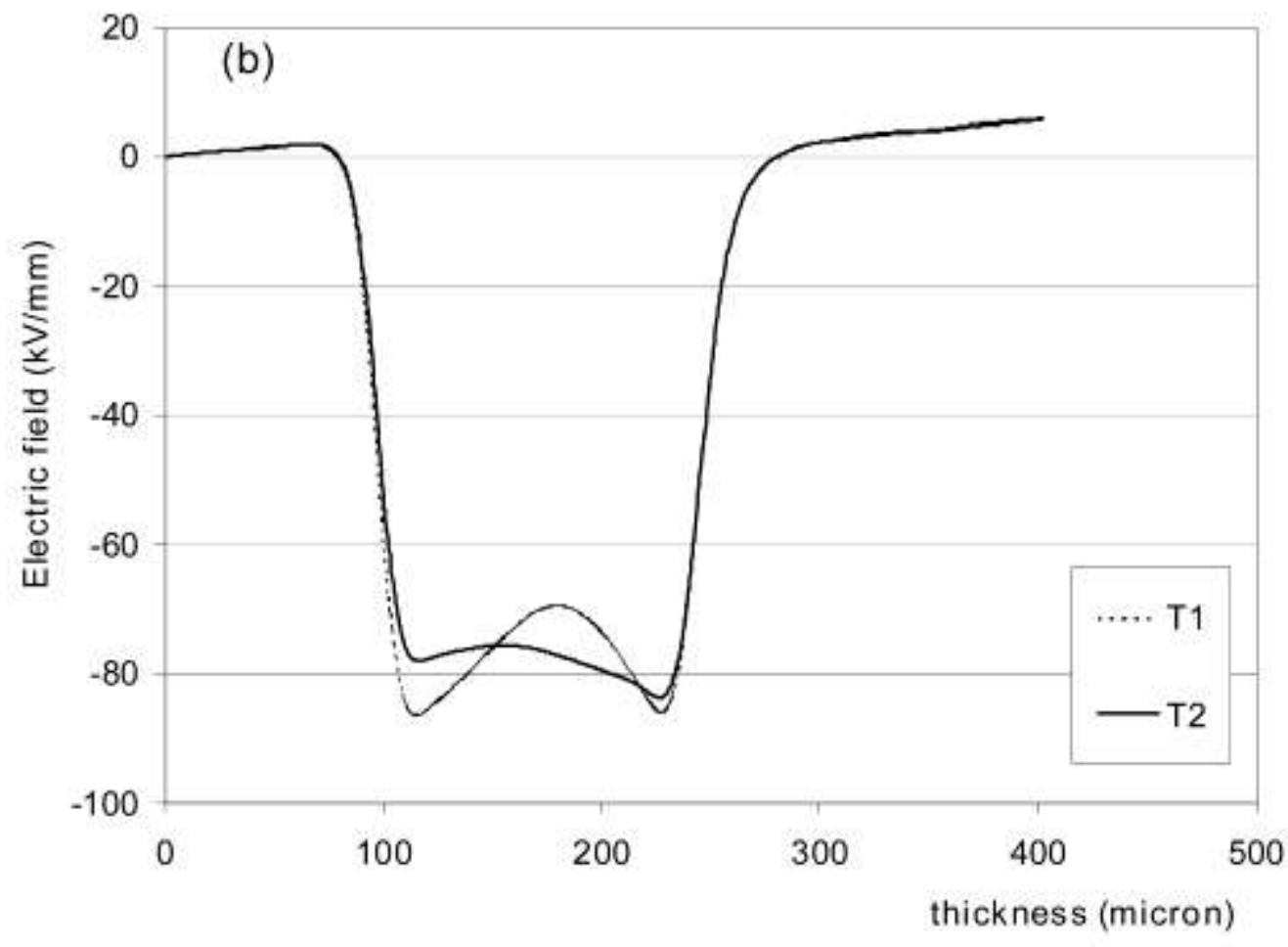

Figure $8 b$ 


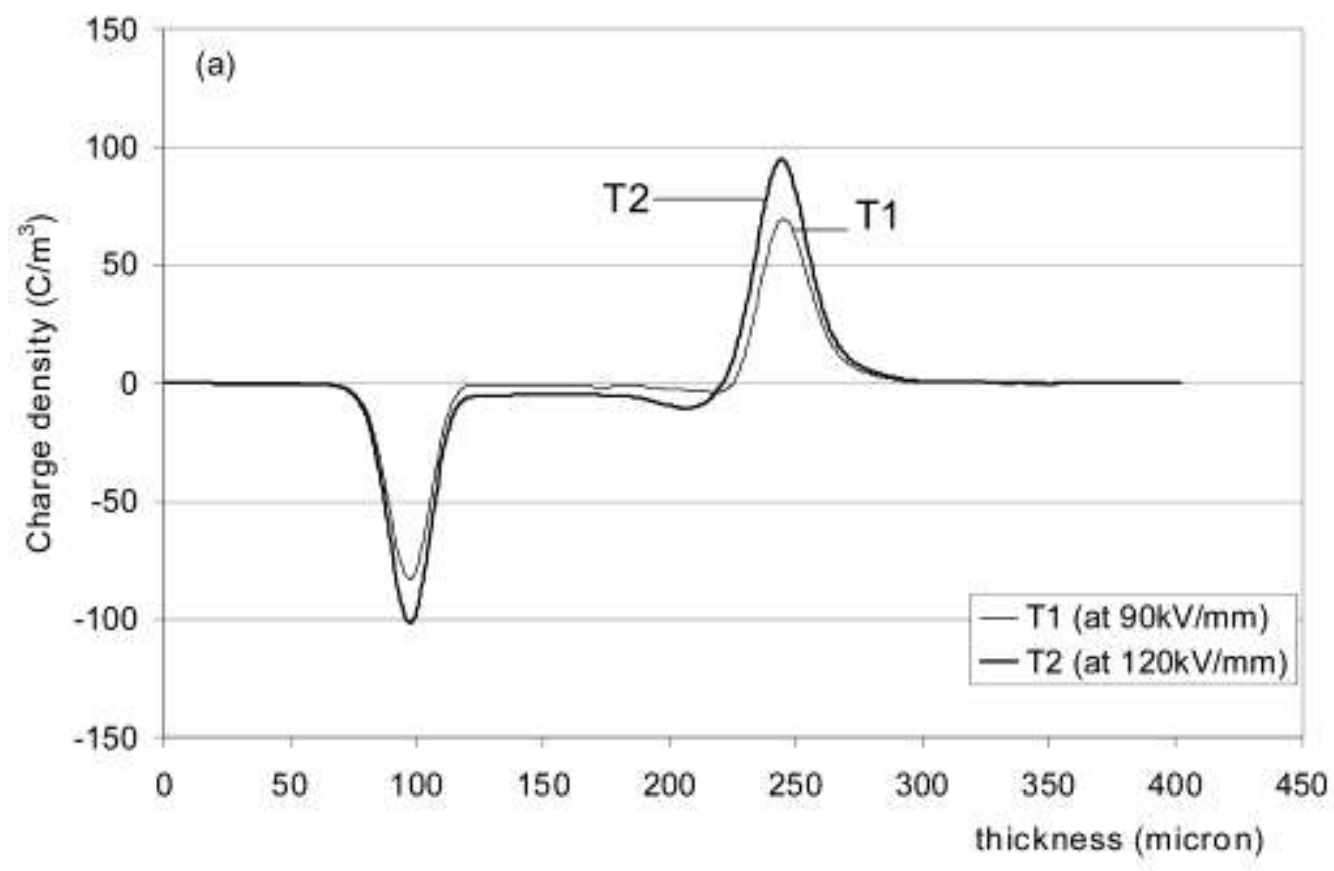

Figure 9a 


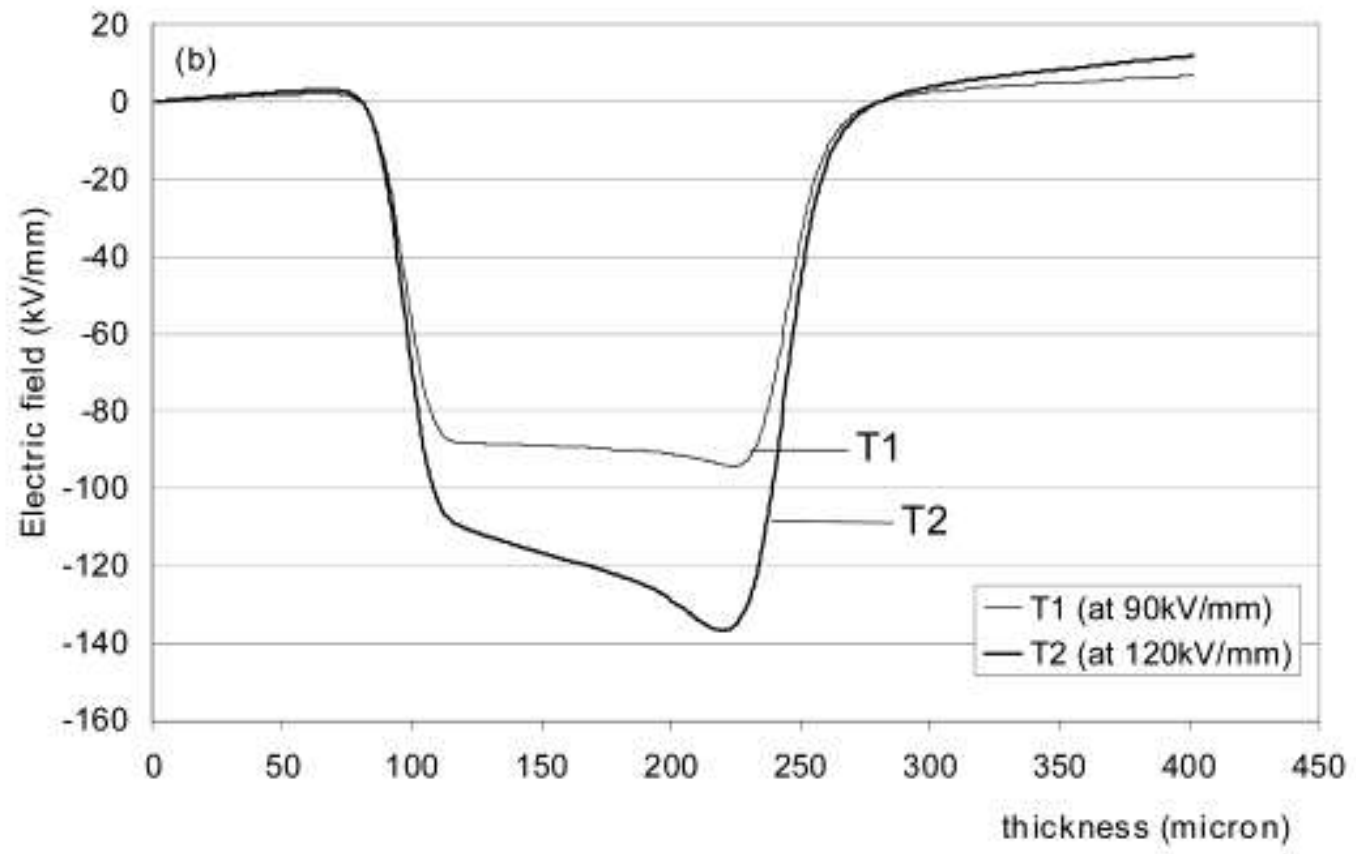

Figure $9 b$ 


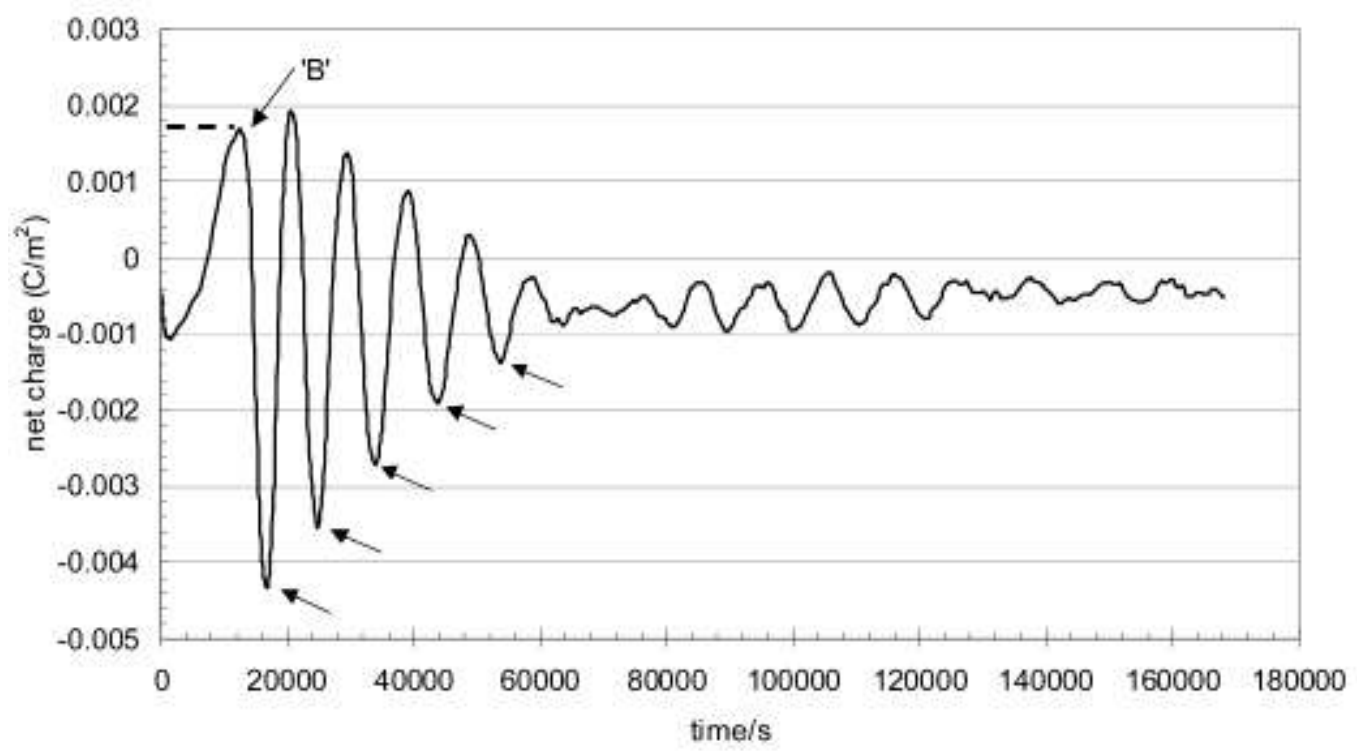

Figure 10 